$\begin{array}{cc}\text { ACADEMIA ROMÂNĂ } & \text { Rev. Roum. Chim., } \\ \text { Revue Roumaine de Chimie } & \text { 205(10), 893-898 } \\ \text { http://web.icf.ro/rrch/ } & \text { DOI: 10.33224/rrch.2020.65.10.04 }\end{array}$

\title{
ESTIMATION OF BIOCIDAL ACTIVITY OF SOME IMIDAZOLINE DERIVATIVES BY USING PATHOGENIC BACTERIAL AND YEAST STRAINS
}

\author{
Anca Mihaela MOCANU, ${ }^{\mathrm{a},{ }^{*}}$ Mariana DIACONU ${ }^{\mathrm{b}}$ and Laura BULGARIU ${ }^{\mathrm{b}}$ \\ a "Gheorghe Asachi” Technical University of Iaşi, Faculty of Chemical Engineering and Environmental Protection, \\ Department of Organic, Biochemical and Food Engineering, Iaşi, Roumania \\ b "Gheorghe Asachi” Technical University of Iaşi, Faculty of Chemical Engineering and Environmental Protection, \\ Department of Environmental Engineering and Management, Iaşi, Roumania
}

The present study is aimed to estimate the biocidal activity of some imidazoline derivatives with potential biological activities such as cardiovascular, analgesic, vasodilating, anti-bacterial, anti-fungal, herbicidal and plant growth regulatory properties The newly obtained compounds were studied for their biocidal activities on two pathogenic bacterial species (Escherichia coli and Staphylococcus aureus) and also on an yeast strain (Candida albicans), in vitro, when their efficiency was estimated by means of the submerged cultivation method and the biomass determination. The compounds under study showed a variable bacterial growth inhibitory activity.

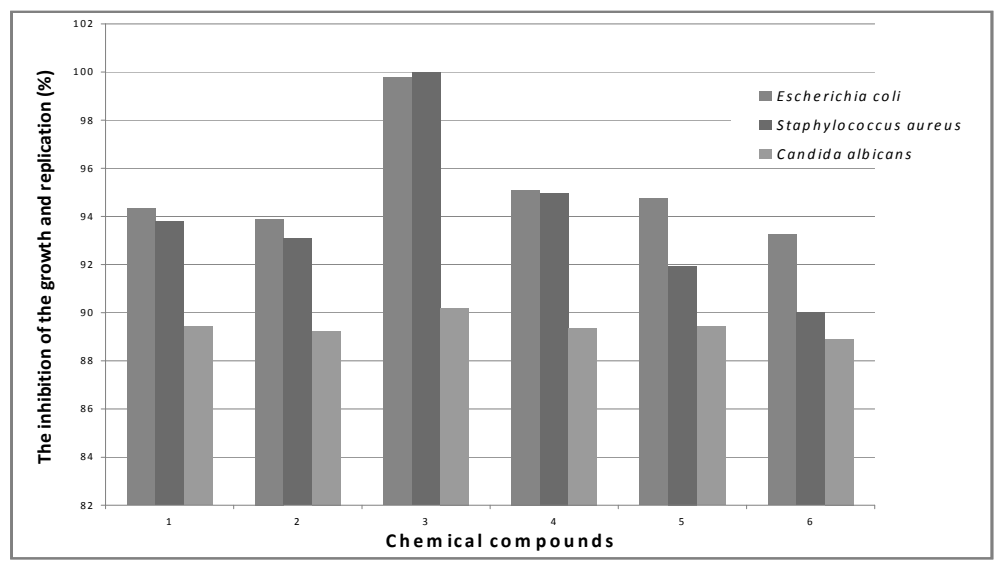

\section{INTRODUCTION}

The imidazolines and their derivatives belong to a large group of biologically active compounds particularly attractive for their distinctive therapeutic applications. $^{1-6}$ The imidazole ring is to be found in the basic structures of proteins, vitamins, several alkaloids and herbicides. ${ }^{7,8}$ Apart from this the substituted imidazolines are also important for being used as intermediates ${ }^{7}$, catalysts and ligands ${ }^{9,10}$ in various chemical reactions. ${ }^{11-14}$ The imidazoline containing compounds are valuable as agents acting at the adrenergic and imidazoline receptors. The aniline-imidazolines are largely used in clinical applications for treating the high blood pressure as well as sedative, anxiolytic and analgesic agents while others act as antagonistic of the adrenergic receptors behaving as vasodilators.

Have been discovered new 2-imidazolinecontaining monoamine oxidase MAO inhibitors, ${ }^{15,16}$ compounds that may be used as future probes for the imidazoline binding sites of the MAOs, and as potential leads for the development of new therapeutic agents.

The objective of the present in vitro study was to test potential antimicrobial activities of new compounds against pathogenic strains of Escherichia coli, Staphylococcus aureus and Candida albicans by submerged cultivation method and biomass determination.

\footnotetext{
*Corresponding author: ancamocanu@ch.tuiasi.ro, ancamocanu2004@yahoo.com
} 


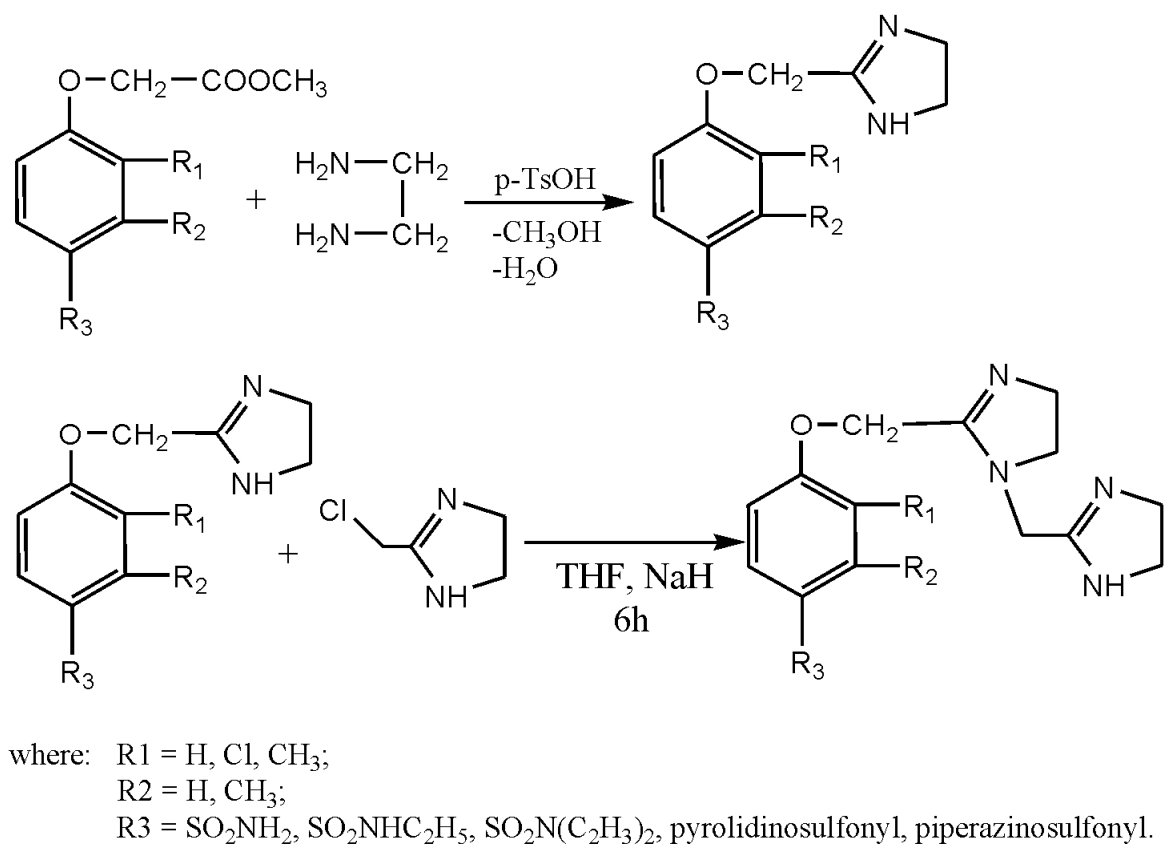

Fig. 1 - The reaction of obtaining 2-[4-(amidosulfonyl- $\mathrm{R}_{1}, \mathrm{R}_{2}$-phenoxymethyl)-methyl]imidazolines.

Table 1

Amount of wett biomass obtained by cultivation pathogenic strains in the presence of chemical compounds

\begin{tabular}{c|c|c|c|c}
\hline \multirow{2}{*}{$\begin{array}{c}\text { Nr. } \\
\text { crt. }\end{array}$} & \multirow{2}{*}{ Compounds } & \multicolumn{3}{|c}{ The wett biomass (g/mL) } \\
\cline { 3 - 5 } & & Escherichia Coli & Staphylococcus Aureus & Candida Albicans \\
\hline 1 & 1 & 0.00832 & 0.00289 & 0.01832 \\
2 & 2 & 0.00895 & 0.00323 & 0.01865 \\
3 & 3 & 0.00033 & 0.00001 & 0.01701 \\
4 & 4 & 0.00719 & 0.00234 & 0.01845 \\
5 & 5 & 0.00769 & 0.00376 & 0.01832 \\
6 & 6 & 0.00988 & 0.00462 & 0.01923 \\
7 & Standard & 0.14667 & 0.04665 & 0.17344 \\
\hline
\end{tabular}

\section{RESULTS AND DISCUSSION}

Synthesis of the 1,2-disubstituted imidazolines involves the initial obtaining of the 2-imidazoline followed by the functionalization of the N-H group by treating with active alkylating agents or by coupling reactions with aryl halides mediated by metals. Then the sodium salts corresponding to the 2-imidazoline derivatives resulting by treating with sodium hydride in anhydrous THF were reacted with 2-chloro-methyl-imidazoline at room temperature leading to N-aryl-2-imidazolines. ${ }^{15,17}$

The newly obtained derivatives were synthesized as described in literature, ${ }^{18-23}$ by the condensation of the $R_{1} R_{2}$ substituted sulfonamides of the methylic esters of the phenoxyacetic acids with ethylenediamine under acid catalysis (p-toluenesulfonic acid $\mathrm{p}-\mathrm{Ts} \mathrm{OH}$ ), followed by coupling the resulting derivatives with 2-chloromethylimidazoline in the presence of sodium hydride in anhydrous THF at room temperature as illustrated in the following reaction Figure 1.

For estimaing the biocidal activity of the chemical compounds compared to the standard samples the experiments were further carried out according to the described methods. A replication proceeds of the microbial strains developed on the solidified culture media with a microbiological loop of colonial fragments from the solid medium and their passing into the liquid medium. ${ }^{24}$ The inoculum grows for 20 hours under aeration and stirring conditions. The sterile flasks contain: $13 \mathrm{~mL}$ of liquid culture medium, $1 \mathrm{~mL}$ of cell suspension previously obtained, $1 \mathrm{~mL}$ of solution of the chemical substance to be tested (Figure 2).

The standard samples contain $14 \mathrm{~mL}$ medium and $1 \mathrm{~mL}$ cell suspension. Then the samples under study and the standard samples were incubated for 72 hours on an orbital shaker under aeration and stirring conditions (240 rpm). 


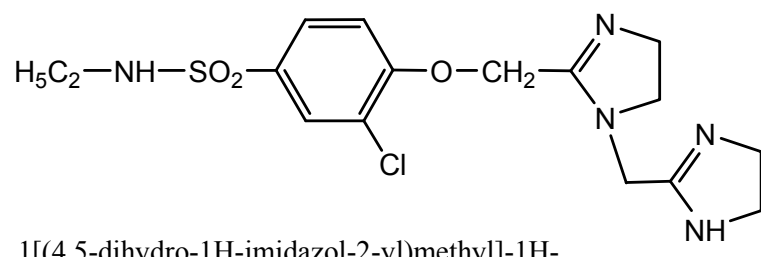

1[(4.5-dihydro-1H-imidazol-2-yl)methyl]-1H-

$\{2-[4-($ ethylaminosulfonyl-2-chloro)fenoxymethyl] $\}$ imidazoline (1)

Chemical formula: $\mathrm{C}_{16} \mathrm{H}_{22} \mathrm{~N}_{5} \mathrm{O}_{3} \mathrm{Cl}$

Molecular weight: 367.5

Melting point: $163-165^{\circ} \mathrm{C}$

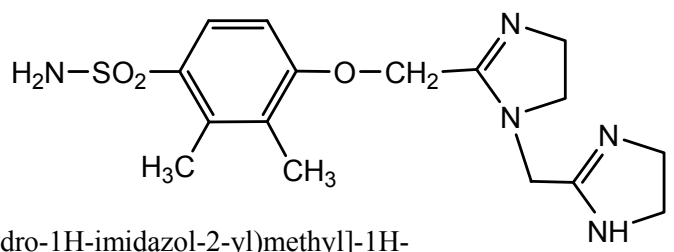

1[(4.5-dihydro-1H-imidazol-2-yl)methyl]-1H-

$\{2-[4-($ aminosulfonyl-2,3-dimethyl)fenoxymethyl] $\}$ imidazoline (2)<smiles>CN(C)S(=O)(=O)c1ccc(OCC2=NCCN2CC2=NCCN2)cc1</smiles>

Chemical formula: $\mathrm{C}_{16} \mathrm{H}_{23} \mathrm{~N}_{5} \mathrm{O}_{3}$

Molecular weight: 333

Melting point: $181-183^{\circ} \mathrm{C}$

\{2-[4-(diethylaminosulfonyl-fenoxymethyl)]\}imidazoline (3)

Chemical formula: $\mathrm{C}_{18} \mathrm{H}_{27} \mathrm{~N}_{5} \mathrm{O}_{3}$

Molecular weight: 361

Melting point: $129-131^{\circ} \mathrm{C}$

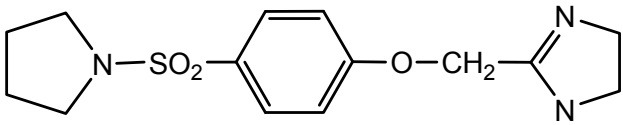

1[(4.5-dihydro-1H-imidazol-2-yl)methyl]-1H-

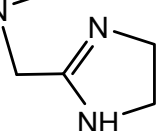

$\{2$-[4-pyrolydinosulfonyl-fenoxymethyl)]\}imidazoline (4) Chemical formula: $\mathrm{C}_{18} \mathrm{H}_{25} \mathrm{~N}_{5} \mathrm{O}_{3}$<smiles>CCN1CCN=C1COc1ccc(S(=O)(=O)N2CCCC2)cc1Cl</smiles>

Molecular weight: 359

Melting point: $132-135^{\circ} \mathrm{C}$

1[(4.5-dihydro-1H-imidazol-2-yl)methyl]-1H-<smiles>CC1=NCCN1</smiles>

\{2-[4-pyrolydinosulfonyl-2-chloro)fenoxymethyl]\} imidazoline (5)

Chemical formula: $\mathrm{C}_{18} \mathrm{H}_{24} \mathrm{~N}_{5} \mathrm{O}_{3} \mathrm{Cl}$

Molecular weight: 393.5

Melting point: $161-163^{\circ} \mathrm{C}$

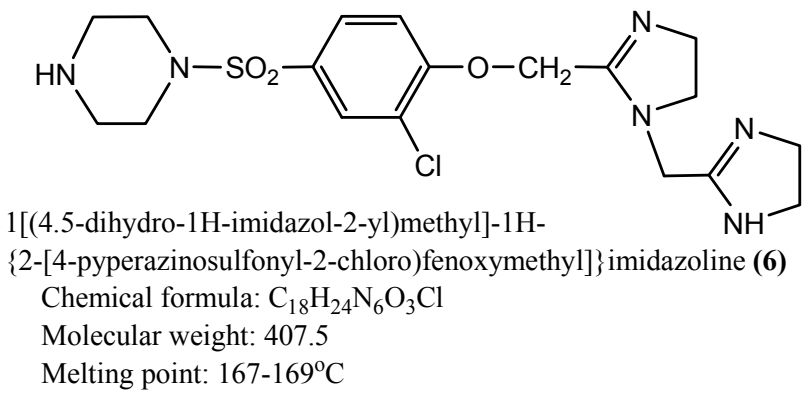

Fig. 2 - The newly synthesized compounds, names and physico-chemical characteristics.

The resulting experimental cultures were used for determining the wett biomass that is the totality of the cells in the culture medium. The mention has to be made that the entire amount of microbial culture in every flask $(15 \mathrm{~mL})$ was passed into centrifuge tubes and the cell mass separated from the liquid by centrifugation. It was weighted on the analytical balance after the complete removal of the liquid and the obtained results (Table 1). 
The following ascertainments come from the data in Table 1: the chemical compounds in the culture medium of the three microbial strains under study had inhibitory effect since the biomass thus obtained was lower than that coming from the standard samples. The amount of wet biomass was different from one microbial strain to another due to the different activity of the chemical compounds on the growth of the tested strains.

The antibacterial activity was detected in the case of the compounds tested, demonstrating that substituents of the type chloro, methyl, dimethyl, pyrolydinosulfonyl or pyperazinosulfonyl, can influence this activity. The sample (3) where the lowest biomass amount was noticed proved to be the most efficient as growing inhibitor of the microbial strains, while the sample (6) was the least efficient. In the case of testing the antibacterial action of compounds (3) and (4) there was highlighted a greater sensitivity of positive Gram bacteria (Staphylococcus aureus) compared with negative Gram bacteria (Escherichia coli) and also on an yeast strain (Candida albicans), phenomenon given by the absence of substituteds of the aromatic ring.

Compunds (1) and (2) influence, also, differentially the development of the microorganisms, demonstrating that substituents of the type chloro and dimethyl of the aromatic ring, was showed highlighted a lower sensitivity of the microbial strains under study. The compunds (4) and (5) presents a the lowest level of sensitivity due the pyrolydinosulfonyl or pyperazinosulfonyl heterocyclic ring, present in the structure.

The data in Table 1 were processed for determining the percentage of growth inhibition of the micro-organisms tested. By assuming a growth inhibition degree of the standard samples of $0 \%$ since there is no factor disturbing the cell growth the results in Figure 3 were obtained.

The plotted results are indicative of the following features: the tested chemical compounds showed an efficiency higher than $85 \%$ for the inhibition of the growth process (growth and replication) of the microbial strains under study.

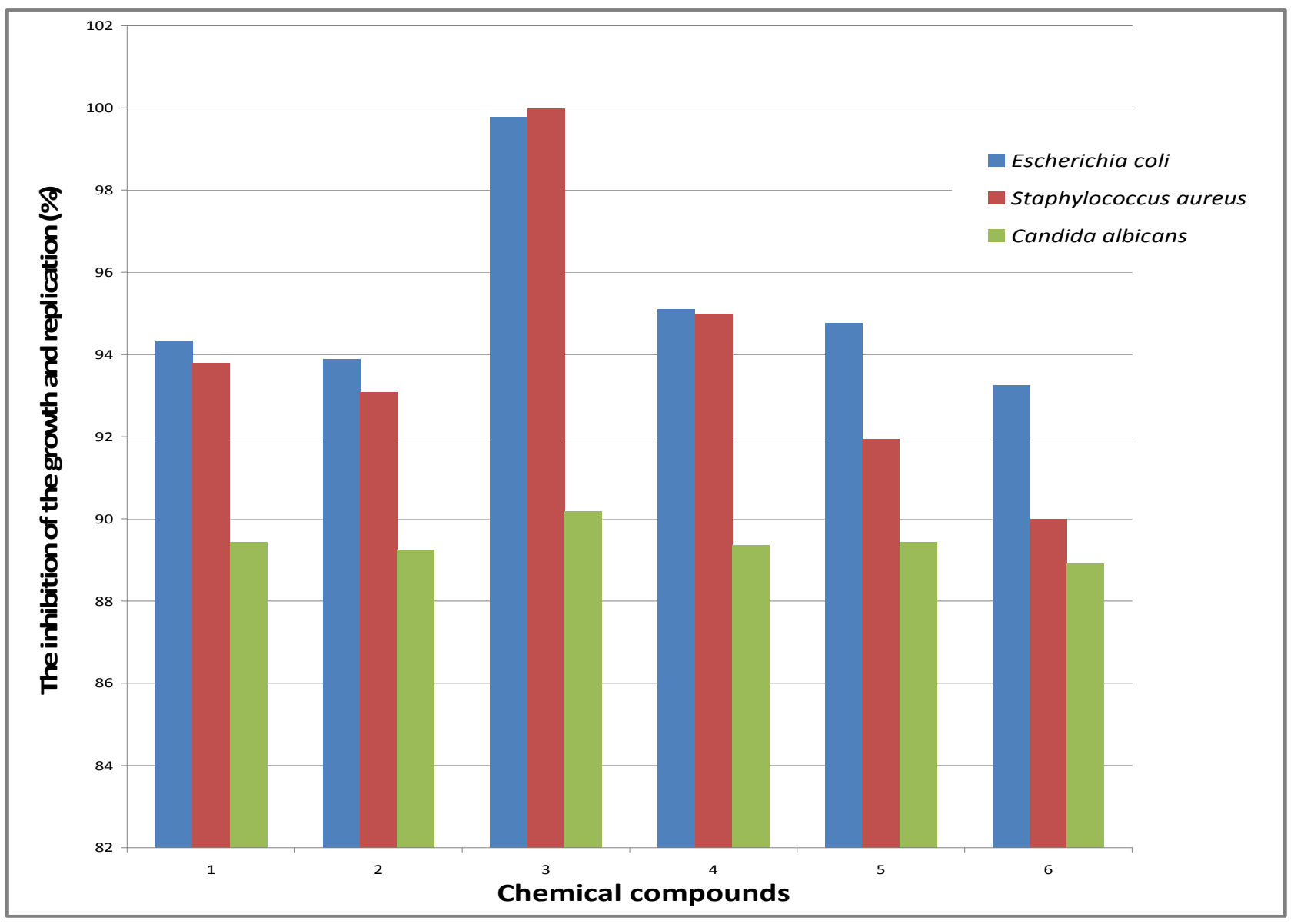

Fig. 3 - The inhibition of the growth and replication process of the microbial strains to the presence of chemical compounds. 


\section{EXPERIMENTAL}

\section{General procedure for the preparation of 2-imidazolines- $\mathrm{N}$-arilates}

The $\mathrm{R}_{1}, \mathrm{R}_{2}$-substituted methylic esters of the phenoxyacetic acids were solved in anhydrous methanol and then the $\mathrm{p}-\mathrm{TsOH}$ and ethylenediamine in anhydrous methanol added. The resulting reaction mixture was refluxed for 4 hours, the methanol removed under vacuum, the remaining residue treated with water and then let to stay till crystallization. The 4-(amidosulfonyl- $\mathrm{R}_{1}, \mathrm{R}_{2}$-phenoxymethyl)-2-imidazoline derivatives thus obtained were finally purified by repeated recrystallizations from water.

To the 4-(amidosulfonyl- $\mathrm{R}_{1}, \mathrm{R}_{2}$-fenoxymethyl)-2-imidazoline solved in anhydrous THF the sodium hydride was added at room temperature and the 2-(chlormethyl)-4,5-dihydro- $1 \mathrm{H}$ imidazole added 15 mintes later stirring then the reaction mixture for 6 hours at room temperature. The resulting $\mathrm{N}$-alkylated products were separated by water addition followed by extraction in dichloromethane. ${ }^{18-23}$

\section{Biological investigations}

The experiments described herein were carried out with solidified and with liquid culture media of a general chemical formulae allowing the growth of a diverse range of microorganisms. The solidified culture medium chosen was the agar YPG medium (Yeast extract-Glucose-Peptone) of the following composition $(\mathrm{g} / \mathrm{L})$ : glucose-20; peptone-10; yeast extract-3; agar-15; distilled water- $1000 \mathrm{~mL} ; \mathrm{pH}=6.8-7.0 ;{ }^{24}$ sterilization under 0.8 at for $20 \mathrm{~min}$. After sterilization and cooling at $40-45{ }^{\circ} \mathrm{C}$ the medium was placed in Petri dishes, let to get solidified and then sown with the micro-organisms to be tested to obtain fresh colonial cultures.

The liquid medium (nutritional broth) taken for obtaining the inoculum of each microbial strain and also for their submerge cultivation had the following composition $(\mathrm{g} / \mathrm{L})$ : glucose-20; meat extract-5; peptone-10; $\mathrm{NaCl}-5$; distiled water-1000 mL; $\mathrm{pH}-7.0{ }^{24}$ sterilization under 0.8 at for 20 minutes. The liquid medium was distributed in Erlenmeyer flasks of $25 \mathrm{~mL}$ for the experiments to be run.

The biocidal activity of the samples was estimated by means of the submerge cultivation method and determination of the wet biomass. The method consists in contacting the samples and the micro-organisms to be tested by cultivating in liquid culture medium under aeration and stirring conditions for 72 hours.

The procedure is developed as follows: firstly, an inoculum is obtained by sowing some colonial fragments of the bacterial or yeast species into the liquid culture medium (nutritional broth) distributed in Erlenmeyer flasks. It is let to stay to grow for 18-20 hours under aeration and stirring conditions.

For the next stage the sterile flasks of $25 \mathrm{~mL}$ capacity are prepared by taking the number of samples into account and then $13 \mathrm{~mL}$ of liquid culture medium placed into each flask. After adding $1 \mathrm{~mL}$ of the cell suspension previously obtained $1 \mathrm{~mL}$ of the chemical substance solution to be tested is finally added. At the same time, for every microbial strain a standard flask containing $14 \mathrm{~mL}$ liquid culture medium and $1 \mathrm{~mL}$ cell suspension is taken. The flasks thus prepared are incubated for 72 hours under aeration and stirring conditions $(240 \mathrm{rpm})$ for the growth of micro-organisms and to reveal the effect of the chemical compounds. When the cultivation period is over the resulting biomass is determined.
The biomass represents the entire amount of microbial cells obtained by growing a micro-organism cultivated for 72 hours in a liquid medium of the optimum formulae for that micro-organism under optimum cultivation conditions (aeration, stirring, temperature).

The biomass was determined by a gravimetrical method (weighting on the analytical balance). On this purpose the previously resulting cell suspensions were quantitatively passed into centrifugation tubes previously weighted at the analytical balance (their weights being noted).

The tubes were centrifuged for 10 minutes at $6000 \mathrm{rpm}$ in order to separate the biomass from the culture medium. The supernatant was thrown off and the tubes arranged in reverse position for removing the liquid traces. The tubes were again weighted at the analytical balance and the results noted. The difference between the final and the initial weights of the tubes gives the total amount of microbial biomass according to the relation:

$$
\text { Total biomass }(m g)=\mathrm{G}_{\mathrm{f}}-\mathrm{G}_{\mathrm{i}}
$$

where:

$\mathrm{G}_{\mathrm{f}}$-stands for the final weight of the tube;

$\mathrm{G}_{\mathrm{i}}$-stands for the initial weight of the tube.

The experimental data were processed for estimating the inhibition degree of biomass due to the toxic component by means of the equation 2 :

$$
\text { Inhibition }(\%)=\frac{C_{w}-S_{w}}{C_{w}} \cdot 100
$$

where:

$\mathrm{C}_{\mathrm{w}}$ - biomass obtained in control (mg);

$\mathrm{S}_{\mathrm{w}}$ - biomass obtained in the samples containing the toxic component (mg).

\section{CONCLUSIONS}

The present study proves that, among structurally highly diverse series of 2-imidazolines, the tested compounds show a good biocidal activity.

These reactions as a new method for the synthesis of practically valuable imidazolidine derivatives open new prospects for their application in the fields of biochemistry, medicine, theoretical and synthetic organic chemistry.

The highest efficiency was noticed against the bacterial strains of Escherichia coli and Staphylococcus aureus, where the inhibition values of the microbial growth exceeded $90 \%$.

The Candida albicans strain was the least sensitive to these compounds as compared to the tested bacterial strains.

The sample (3) was found to be the most efficient for the biocidal properties with all tested strains where the highest values of the growth inhibition degree were found. 


\section{REFERENCES}

1. E. I. Klimova, M. Flores-Alamo, S. Cortez Maya, J. C. García-Ramos, L. Ortiz-Frade and J. M. Méndez Stivalet, J. Organomet. Chem., 2013, 743, 24-30.

2. T. Eicher and S. Hauptmann, "The Chemistry of Heterocycles, Structures, Reactions, Synthesis and Applications", Wiley-VCH GmbH \& Co. KGaA, Weinheim, 2006, p. 234-236.

3. H. Liu and D.-M. Du, Adv. Synth. Catal., 2009, 351, 489- 519.

4. C. Congiu, M. T. Cocco and V. Onnis, Bioorg. Med. Chem. Lett., 2008, 18, 989-993.

5. M. Su Han and D. H. Kim, Bioorg. Med. Chem. Lett., 2001, 11, 1425-1427.

6. G. Roman, J. G. Riley, J. Z. Vlahakis, R. T. Kinobe, J. F. Brien, K. Nakatsu and W. A. Szarek, Bioorg. Med. Chem., 2007, 15, 3225-3234.

7. F. Rondu, S. Le Bihan, G. X. Wang, A. Lamouri, E. Touboul, G. Dive, T. Bellahsene, B. Pfeiffer, P. Renard, B. Guardiola-Lemaitre, D. Manechez, L. Penicaud, A. Ktorza and J. J. Godfroid, J. Med. Chem., 1997, 40, 3793-3799.

8. A. M. Venkatesan, A. Agarwal, T. Abe, H. O. Ushirogochi, D. Santos, Z. Li, G. Francisco, Y. I. Lin, P. J. Peterson, Y. Yang, W. J. Weiss, D. M. Shales and T. S. Mansour, Bioorg. Med. Chem., 2008, 16, 1890 -1902.

9. P. Bousquet and J. Feldman, Drugs, 1999, 58, 799- 812.

10. T. Isobe, K. Fukuda, Y. Araki and T. Ishikawa, Chem. Commun., 2001, 243-244.

11. P. Bousquet and J. Feldman, Drugs, 1999, 58, 799-812.

12. M. Ueno, K. Imaizumi, T. Sugita, I. Takata and M. Takeshita, Int. J. Immunipharmacol., 1995, 17, 597-603.
13. M. E. Jung and A. Huang, Org. Lett., 2000, 2, 26592661.

14. P. Mujumdar, P. Sarnpitak, A. Shetnev, M. Dorogov and M. Krasavin, Tetrahedron Lett., 2015, 56, 2827-2831.

15. A. Shetnev, A. Osipyan, S. Baykov, A. Sapegin, Z. Chirkova, M. Korsakov, A. Petzer, I. Engelbrecht and J. P. Petzer, Bioorg. \& Med. Chem. Lett., 2018, 29, 40-46.

16. C. Binda, P. Newton-Vinson, F. Hubalek, D. E. Edmondson and A. Mattevi, Nat Struct Biol., 2002, 9, 22-26.

17. J. Saczewski, A. Hudson, M. Scheinin, A. Rybczynska, D. Mae, F. Saczewski, S. Laird, J. M. Laurila, K. Boblewski, A. Lehmann, J. Gu and H. Watts, Bioorg. Med. Chem., 2012, 20, 108-116.

18. C. Soldea, C. Oniscu and V. Sunel, Rev. Med. Chir. Soc. Med. Nat., 1992, 96, 265-268.

19. V. P. Radha, S. J. Kirubavathy and S. Chitra, J. Molec. Struc., 2018, 1165, 246-258.

20. G. Lazorenko, A. Kasprzhitskii and V. Yavna, Chem. Physics Lett., 2018, 692, 264-270.

21. G. Caprioli, V. Mammoli, M. Ricciutelli, G. Sagratini, M. Ubaldi, E. Domi, L. Mennuni, C. Sabatini, C. Galimberti, F. Ferrari, C. Milia, E. Comi, M. Lanza, M. Giannella, M. Pigini and F. Del Bello, Eur. J. Pharm., 2015, 769, 219-224.

22. R. G. Campbell, S. Nair, R. Sacks and R. G. Douglas, Med. Hypot., 2014, 82, 706-708.

23. R. Li, H. Jiang, W. Y Liu, P. M. Gu and X. Q. Li, Chin. Chem. Lett., 2014, 25, 583-585.

24. V. L. Pavel, M. Diaconu, D. Bulgariu, F. Statescu and M. Gavrilescu, Environm. Engin. Managem. J., 2012, 11, 165-168. 